\title{
Arqueologia da R.U.A : narrativas em Realidade. Urbana. Aumentada. Quando o encontro se transforma em um território artístico, coletivo e expandido
}

\section{LILIAN AMARAL}

Resumo

A presente discussão objetiva investigar os modos de fazer artísticos colaborativos que se configuram no âmbito de uma geopolítica líquida, apropriam-se do "espaço-tempo" diante de um modelo participativo e compartilhado das redes, através dos processos de transformação dos territórios, considerando suas implicações culturais, ecológicas, políticas, sociais e tecnológicas, tendo a criatividade social, a ação coletiva e as práticas artísticas contemporâneas como eixos temáticos para inovadoras plataformas de intervenções urbanas.

Palavras-chave:

Arte colaborativa, geopolítica, intervenções urbanas 


\section{R.U.A.: Augmented Urban Reality. When the meeting turns into an artistic, collective and expanded territory}

\section{LILIAN AMARAL}

Keywords: Collaborative art, geopolitics, urban interventions

\section{Abstract}

The present discussion aims to investigate ways of making collaborative art configured as a field of a liquid geopolitical, appropriate "space-time" before a participatory model and shared networks, trough territories transformation processes, considering its cultural, ecological, political, social and technological implications, based on social creativity, collective action and contemporary artistic practices as thematic platforms for innovative urban interventions. 


\section{Introdução}

\section{Mobilidade como instância criadora de sentido: potencial performativo da cidade contemporânea}

A configuração das cidades seria outra se usássemos nosso corpo-andante de outro jeito. Flanar, vagar, derivar, errar configuram-se como motores para pensarmos para além da arquitetura sedimentada, desviando-nos para perseguir a possibilidade de uma "cidade performativa". Trata-se do deambular como arquitetura da paisagem, do caminhar como forma de arte autônoma, ato primário de transformação simbólica do território, instrumento estético de conhecimento e modificação física do espaço "atravessado" que se converte em intervenção urbana.

Praticar o lugar - real e imaginário individual e coletivo, público e privado, material ou existencial - revela paisagens potenciais que instigam a experiência urbana e legitimam a intervenção e ocupação performativas como ação transformadora. Propõe-se atuar a partir de métodos inspirados em práticas urbanísticas que adotam o caminhar como prática estética, entendendo a corporalidade urbana como instância que desfaz a ideia do corpo como categoria genérica e impõe a necessária apreensão das especificidades locais.

Do nomadismo primitivo ao Dadaísmo e Surrealismo, da Internacional Letrista à Internacional Situacionista e do Minimalismo à Land Art, os métodos e processos desenvolvidos abordam a percepção da paisagem através de uma história da cidade percorrida. Por subsidiar modos de experimentar artisticamente as cidades, engajando corporalidade e devir, as ideias engendradas por tais práticas contemporâneas vem 
ganhando espaço e inspirando coreógrafos, performers e artistas que trabalham com arte urbana.

Transitar entre territórios converteu-se em condição humana contemporânea marcada pelo deslocamento, fluxo e aceleração. Territórios entendidos como contextos definem os lugares de existência. Territórios culturais, étnicos, religiosos parecem definir melhor a noção contemporânea de lugar.

Diálogos cada vez mais intensos vêm configurando uma nova cartografia cognitiva caracterizada por colaborações entre diferentes territórios e domínios, colocando em evidência as possibilidades de compartilhamento de estratégias pautadas pela complementaridade, interrelacionamento e reciprocidade entre campos: a História da Arte, a Estética, a Teoria Cinematográfica, os Estudos Culturais, a Teoria dos Meios, a Arte/ Educação, a Cultura Visual, os Estudos de Gênero, entre outros.

Que lugares, num mundo marcado pelo nomadismo, impermanência e simultaneidade as manifestações artísticas podem ocupar? A informação e a comunicação que caracterizam a cidade contemporânea vêm se tornando cada vez mais agudamente crítica para transcender a sociedade de consumo. Tudo está para ser visto, consumido, refletido, assumido ou descartado (AMARAL \& BARBOSA, 1998).

Arqueologia da R.U.A., investigação em processo, incorpora as tensões, fluxos e mediações ocorridas nas fronteiras entre território público e privado, entre ética e estética, entre individual e coletivo, entre memória e imaginário, tendo a potência, fraturas e interrupções da cidade de São Paulo como lugar de experiência, atuação crítica e criativa. Convoca artistas e não artistas, coletivos interdisciplinares e a população para interagir, por meio de pensamentos, ações e atitudes simbólicas nos espaços públicos, re-significando a experiência urbana cotidiana.

Os significados de uma obra ou ação artística são construídos no encontro entre a subjetividade daquele que a propõe e a subjetividade de cada um daqueles que ativamente a tomaram para si. No entanto, no momento em que a proposição começa a tomar forma e o momento em que é ativada, por um e por outro sujeito, deve haver um desejo de alcance público. Quando se decide apresentar publicamente o resultado ou o processo de um pensamento é porque se acredita que ele pode ser pertinente para outros. E não somente para aqueles com quem sabidamente nos entendemos e frequentemente nos encontramos, mas também para outros com quem compartilhamos coisas que talvez ainda não tenham nome. 
Arqueologia da R.U.A. configura-se como laboratório transdisciplinar em processo e propõe considerar que tanto os métodos de análise contemporâneos das disciplinas urbanas quanto o que poderia ser visto como um de seus resultados projetuais, a cidade-espetáculo, se distanciam cada vez mais da experiência urbana, da própria vivência ou prática da cidade. Ser errante poderia ser um instrumento desta experiência urbana, uma ferramenta subjetiva e singular, ou seja, o contrário de um método ou de um diagnóstico tradicional. A errância urbana seria uma apologia da experiência da cidade, um tipo de ação que poderia ser praticada por qualquer um. Um dispositivo para ampliação da percepção.

Os praticantes das cidades atualizam os projetos urbanos, e o próprio urbanismo, através da prática dos espaços urbanos. Os urbanistas indicam usos possíveis para o espaço projetado, mas são aqueles que o experimentam no cotidiano que os atualizam. São diferentes ações, apropriações ou improvisações mediadas pelo pensamento crítico apontado pela Arte Pública Relacional Contemporânea e as interfaces tecnológicas que podem propor extrapolar a circunscrição das experiências nos espaços convencionados ao consumo privado da arte em direção aos espaços da vida, das experiências no [ciber]espaço público pelos habitantes, passantes, viajantes ou errantes que reinventam tais espaços em seu cotidiano.

Enquanto o urbanismo busca a orientação através de mapas e planos, a preocupação do errante estaria mais na desorientação, sobretudo em deixar seus condicionamentos urbanos, uma vez que toda a educação do urbanismo está voltada para a questão do se orientar, ou seja, o contrário mesmo do "se perder". Em seguida, pode-se notar a lentidão dos errantes, o tipo de movimento qualificado dos homens lentos, que negam, ou lhes é negado, o ritmo veloz imposto pela contemporaneidade. E por fim, a própria corporeidade destes, e, sobretudo, a relação, ou contaminação, entre seu próprio corpo físico e o corpo da cidade que se dá através da ação de errar pela cidade. A contaminação corporal leva a uma incorporação, ou seja, uma ação imanente ligada à materialidade física, corporal, que contrasta com uma pretensa busca contemporânea do virtual, imaterial, incorporal.

As três propriedades mais recorrentes das errâncias - se perder, lentidão, corporeidade - estão intimamente relacionadas, e remetem a própria ação, ou seja, a prática ou experiência do espaço urbano. $\mathrm{O}$ errante urbano se relaciona com a cidade, a experimenta, e este ato de se relacionar com a cidade 
implica nesta corporeidade própria, advinda da relação entre seu próprio corpo físico e o corpo urbano que se dá no momento da desterritorialização lenta da errância. Para resumir, pode-se dizer que o errante faz seu elogio à experiência principalmente através da desterritorialização do ato de se perder, da qualidade lenta de seu movimento e da determinação de sua corporeidade. As três propriedades poderiam ser consideradas como resistências ou críticas ao pensamento hegemônico contemporâneo do urbanismo que ainda busca uma certa orientação (principalmente através do excesso de informação), rapidez (ou aceleração) e, sobretudo, uma redução da experiência e presença física (através das novas tecnologias de comunicação e transporte).

Apesar da íntima relação entre essas propriedades da errância, talvez seja a relação corporal com a cidade, na experiência da incorporação, que mostre de forma mais clara e crítica, o cotidiano contemporâneo cada vez mais desencarnado e espetacular. Diante da atual espetacularização das cidades que se tornam cada dia mais cenográficas, a experiência corporal das cidades, ou seja, sua prática ou experiência poderia ser considerada como um antídoto a essa espetacularização. $\mathrm{O}$ que chamamos de espetacularização das cidades contemporâneas - que também pode ser chamado de cidade-espetáculo (no sentido debordiano) - está diretamente relacionado a uma diminuição da participação, mas também da própria experiência urbana enquanto prática cotidiana, estética ou artística.

A redução da ação urbana pelo espetáculo leva a uma perda da corporeidade, os espaços urbanos se tornam simples cenários, sem corpo, espaços desencarnados. Os espaços públicos contemporâneos, cada vez mais privatizados ou não apropriados, nos levam a repensar as relações entre urbanismo e corpo, entre o corpo urbano e o corpo do cidadão, o que abre possibilidades tanto para uma crítica da atual espetacularização urbana quanto para uma pesquisa de outros caminhos pelos errantes urbanos, que passariam a ser os maiores críticos do espetáculo urbano.

Ao se observar mais de perto a história crítica do urbanismo, a história marginal, é possível se perceber outro caminho, que critica a espetacularização desde seus primórdios. Nesta pista, as principais questões são as diferentes formas de ação e participação na cidade, mas também as relações corporais, através das experiências efetivas dos espaços urbanos. As relações sensoriais com a cidade que passam pelas experiências corporais destes espaços, em suas diferentes temporalidades, 
seriam o oposto da imagem da cidade-logotipo. Os cenários ou espaços espetacularizados, desencarnados, seriam propícios somente para os simples espectadores.

Os praticantes da cidade, como os errantes urbanos, realmente experimentam os espaços quando os percorrem, e assim lhes dão corpo, e vida, pela simples ação de percorrê-los. Uma experiência corporal, sensorial, não pode ser reduzida a um simples espetáculo, a uma simples imagem ou logotipo. A cidade deixa de ser um simples cenário no momento em que ela é vivida, experimentada. Ela ganha corpo a partir do momento em que ela é praticada, se torna "outro" corpo. Para o errante urbano sua relação com a cidade seria da ordem da incorporação. Seria precisamente desta relação entre o corpo do cidadão e deste outro corpo urbano que poderia surgir outra forma de apreensão da cidade, outra forma de ação, através da experiência da errância - desorientada, lenta e incorporada - a ser realizada pelo urbanista errante, que se inspiraria de outros errantes urbanos e, em particular, das experiências realizadas pelos escritores e artistas errantes.

O flanar, vagar, derivar, errar também se configuram como ordenadores do pensamento que se colocam para além da arquitetura estável e sedimentada, desviando-se em direção a possibilidade de uma "cidade performativa".

Nossa proposta é analisar as etapas de elaboração, desenvolvimento e desdobramentos de um processo baseado na criação artística interativa: Arqueologia da R.U.A. habita o território urbano a partir dos conceitos de "espaço-tempo" dando ênfase aos signos estéticos e tendo como elemento primordial a desconstrução de dicotomias que se circunscrevem ao objeto artístico. Transitar entre as mediações, interfaces, processos e fluxos parece ser um dos dilemas enfrentados pelas artes hoje.

Nas dinâmicas sociais e práticas produtivas e no uso dos meios digitais que convergem e hibridizam-se, identificam-se elementos como a ubiquidade, pervasividade, liquidez dos "territórios" que passam a reconfigurar o espaço urbano, real e virtual. $\mathrm{O}$ foco da presente investigação centra-se nos modos de fazer artísticos que se apropriam do "espaço-tempo" diante de um modelo compartilhado nas redes e através dos processos de transformação dos territórios e de suas implicações políticas, sociais e tecnológicas no tecido urbano.

Hoje, observa-se que o campo da arte se expande para além da forma, busca encontrar meios de se fazer objeto através das tecnologias digitais dando significado a tudo o que se acreditava ser estável e instável ao mesmo tempo. Diante de 
uma nova dimensão estética na produção artística contemporânea, a ênfase recai no fluxo e não mais na forma, cedendo lugar ao informe, aleatório, efêmero e transitório (COSTA, 1995). Para Gilles Deleuze, a arte é portadora de processos calcados no "devir" (1997). A arte

atinge esse estado celestial que já nada guarda de pessoal nem racional. À sua maneira, a arte diz o que dizem as crianças. Ela é feita de trajetos e devires, por isso faz mapas, extensivos e intensivos. Há sempre uma trajetória na obra de arte [...] E como os trajetos não são reais, assim como os devires não são imaginários, na sua reunião existe algo único que só pertence à arte. [...] À arte-arqueologia, que se funda nos milênios para atingir o imemorial, opõe-se uma arte-cartografia, que repousa sobre as coisas do esquecimento e os lugares de passagem (DELEUZE, 1997, p.67-68).

A função do artista não é mais exclusivamente aquela de exprimir-se ou de dar forma ao objeto artístico, mas de criar dispositivos e interfaces comunicacionais nas quais as dimensões do "acontecimento" e do "devir" (ZOURABICHVILI, 2009, p.6 e 24) tornam-se conscientes de si e se revelam ao sensível. As tecnologias da informação e comunicação alteram as noções de próximo e distante, de vizinhança, de ausência e presença, de espaço e tempo revelando o enfraquecimento do sujeito e o fortalecimento das subjetividades. A noção clássica de ordem, medida e de objetos mensuráveis perde o sentido original e tudo fica, ao mesmo tempo, ordenado e caótico, finito e infinito, livre dos sistemas e, ao mesmo tempo, inserido neles. A uniformidade gerada, onde as coisas não estão nem longe nem perto, produzem a dimensão espacial das infinitudes. A cartografia dos fluxos gera a dimensão da "ausência" como algo presente criado pelas tecnologias digitais e, assim, os artistas passam a trabalhar "dando forma ao vazio" (COSTA, 1995). O espaço é abstrato e concebe a noção de vazio.

Para Milton Santos (2004) o processo de virtualização das redes permitiu observar novos espaços e novos formatos de explicitação dos objetos e de suas representações espaciais. A ausência de distância, a telepresença, a ubiqüidade, a possibilidade de comunicação à distância em tempo real reduziram o tempo em favor de uma espacialização mais leve e fluída.

Animadas por fluxos, que dominam o seu imaginário, as redes não prescindem de fixos - que constituem suas bases téc- 
nicas - mesmo quando esses fixos são pontos. Assim, as redes são estáveis e, ao mesmo tempo, dinâmicas. Fixos e fluxos são intercorrentes, interdependentes. Ativas e não-passivas, as redes não têm em si mesmas seu princípio dinâmico, que é o movimento social (SANTOS, 2004, p. 98).

O espaço pode ser entendido como um conjunto de fixos (nós) e fluxos (conexões). Os fixos, em cada lugar, permitem ações que os modificam. Os fluxos recriam as condições ambientais e sociais e redefinem o lugar. Os objetos fixos são organizados através dos fluxos e são acionados segundo uma determinada lógica. Não são os objetos que formam o espaço, mas sim, os espaços que os formam, pois a estrutura lógica que o subjaz determina quais objetos serão destacados e como eles se organizarão. O espaço é sintático. Ele é definido por axiomas e modelado através das transformações gerando postulados, lemas e teoremas.

O lugar é uma porção do espaço que possui significado. É uma parte do espaço que se transforma em significados construídos à partir de uma determinada estrutura lógica. O lugar é essencialmente cultural e social. Ele é uma porção do espaço sem limites ou sem dimensões precisas. Possui elementos significados especulares, ou seja, significados onde os usuários (indivíduos ou grupos) encontram-se e através destes significados identificam os outros que compartilham os mesmo lugares. O lugar é semântico e como tal possui características significantes dadas pelas relações que podem ser construídas nele. Estas relações associam a porção de espaço aos signos definidos nesta fatia de espaço. O lugar é uma porção de espaço que denota. Ele possui uma correlação factual com a realidade.

Por fim, olhamos para o território, que, assim como o lugar, é uma porção do espaço que também possui significado e cujos elementos são signos e valores que refletem a cultura de uma pessoa ou grupo em um determinado momento histórico. Entretanto, na constituição de um território, essa significação é a forma de marcar os elementos do espaço com valores culturais e sociais, de modo que qualquer outro objeto, ação ou indivíduo que se envolva nesta porção de espaço deva se guiar, ou mais, deva se submeter a essa medida cultural e social imposta ao espaço. O território é contextual, pragmático e está carregado de intenções ideológicas, portanto, histórico. Ele possui um nível conotativo de leitura que é simbólico.

Diante desse panorama que caracteriza o lugar da arte contemporânea e seus embates espaciais e temporais e que 
geram implicações nos modos de fazer artístico, observamos que o artista opera de forma processual e colaborativa, evocando ideais do campo da geometria, geografia e cartografia. Para Milton Santos (2000, p.108), "as horizontalidades são zonas de contigüidade que formam extensões contínuas", configurando o que François Perroux (1982, p.473) denomina de "espaço banal", e o que corresponderia às representações espaciais: instituições sociais, corporais, econômicas, virtuais, enfim, territórios de vivência. Em tal território, conforme o geógrafo brasileiro,

todos os agentes são, de uma forma ou de outra, implicados, e os respectivos tempos, mais rápidos ou mais vagarosos, são imbricados. [...] Em tais circunstâncias pode-se dizer que a partir do espaço geográfico cria-se uma solidariedade orgânica, o conjunto sendo formado pela existência comum dos agentes exercendo-se sobre um território comum. Nas horizontalidades funcionam, ao mesmo tempo, vários relógios, realizando-se, paralelamente, diversas temporalidades (SANTOS, 2000, p.111-112).

Desta forma, territorialidades e temporalidades operam um constante tensionamento estabelecendo relações que estão no "espaço-tempo" e que olham para os fixos e fluxos e resultam na readaptação às novas formas de existência. Entendemos que tal processo é aquele pelo qual uma sociedade e um território estão sempre à busca de sentido e exercem, por isso, uma vida reflexiva. Assim, ainda segundo Milton Santos,

o território não é apenas o lugar de uma ação pragmática, [...] comporta, também, um aporte da vida, uma parcela de emoção, que permite aos valores representar um papel. $\mathrm{O}$ território se metamorfoseia em algo mais do que um simples discurso e, constitui um abrigo (SANTOS, 2000. p.115).

\section{MidiaCity: ubiquidade e mobilidade urbana}

As mídias digitais e particularmente as mídias locativas são as possibilidades de vigilância e conexão, de controle e invasão, de inclusão e exclusão, de privacidade e participação. O termo mídia locativa vem sendo utilizado pelos artistas e ativistas sociais para diferenciarem-se dos processos baseados em localização. São intervenções tecnológicas baseadas 
em localização que utilizam os laptops, smartphone, GPS, sensores como etiqueta de rádio freqüência que substituem os códigos de barra, artefatos, dispositivos e redes: tecnologia de celulares, entre elas $3 \mathrm{G}$, bluetooth de curto alcance, internet sem fio, wifi e redes dos satélites artificiais. Tudo que se utiliza de dispositivos móveis e tem serviços baseados em sistemas de localização.

Para produzir informação com sentido e que possa trazer uma nova discussão sobre o espaço, o lugar e o território, associado a temporalidade e seus vínculos sociais, objetiva-se problematizar e questionar o estatuto dessa mobilidade e como pode ser utilizada. Nesta esfera de abordagem operam-se questionamentos singulares acerca da configuração desse espaço de mobilidade e de como é possível produzir, consumir e distribuir informações na mobilidade. De que maneira podemos nos apropriar das tecnologias móveis e de localização para produzir obras artísticas que possibilitem interações no território? E ainda, qual estética corresponde às tecnologias baseadas na localização?

Para André Lemos um sistema com estas características deve ser denominado de pós-massivo e estão produzindo conteúdo com mídias interativas e locativas. Estas introduzem possibilidades de produção de conteúdo livre, isto é, não há controle sobre a produção e muito menos sobre as formas de distribuição. Qualquer pessoa pode produzir e distribuir conteúdos em diversos formatos. Para o autor, a grande radicalidade não está no consumo ou na produção de conteúdos, mas sim, na sua distribuição (LEMOS, 2008).

Os blogs, podcast, wikis, redes sociais, softwares livres remetem a essa dimensão de uma transversalidade da mídia. Não necessitamos da concessão do estado ou das grandes instituições para produzir informação. Esse sistema está baseado na liberação de quem emite a informação, na conexão generalizada que permite a conectividade com outras pessoas e sistemas: blogs, softwares livres (altera os códigos através de uma rede global de produtores) e na reconfiguração da paisagem midiática contemporânea. $\mathrm{O}$ fato de não se estar ligado às grandes corporações, empresas e sistemas governamentais produz uma discussão interessante que engloba os softwares proprietários e livres, os direitos autorais, os conceitos de copyright e copyleft, a construção de subjetividades mediadas pelos dispositivos e interfaces digitais que se configuram em padrões baseados nas redes; nos fixos e fluxos. 


\section{Observatório nômade: dispositivo itinerante. Mobilidade, coletividade e conectividade}

As questões aqui apresentadas configuram-se como corpus da "pesquisa-ação" em processo "Arqueologia da R.U.A: Realidade. Urbana. Aumentada”. Estrutura-se a partir da utilização de redes e dispositivos móveis na função de mídia locativa, visando a criação de circuitos e percursos no território, cartografias colaborativas de narrativas audiovisuais e do imaginário urbano contemporâneo, tendo como território e campo de investigação artístico-cultural o bairro do Bom Retiro e Barra Funda, situados na região central da cidade de São Paulo.

A obra processual colaborativa consiste na criação e ativação de um circuito temporário de interações artísticas, perforgrafias [performances e cartografias] exploratórias das superfícies urbanas, interculturais, ambientais e educativas nos bairros do Bom Retiro e Barra Funda, tendo como elementos de articulação entre as diversas ações participativas de caráter coletivo, a criação de um dispositivo expositivo para veicular atividades específicas e impulsionar ações no território. Opera com a ideia de exposição expandida. Configura-se como um ativador, emissor-receptor, interator de dados, e seu caráter itinerante permite incidir em aspectos específicos do espaço eco-social tendo a mobilidade como elemento de conexão e interação.

A obra também propõe a construção de um sistema em rede on-line que organiza um grande banco de dados com imagens fotográficas, vídeos, registros sonoros, textos e informações e que utiliza a ferramenta computacional API para uso na internet. Esse sistema irá apropriar-se de mapas, diagramas, informações e dados que serão organizados através de diversas narrativas e utilizarão sistemas de organização georeferenciados. A API - Application Programming Interface (Interface de Programação de Aplicações) é um conjunto de rotinas e padrões estabelecidos por software para a utilização de funcionalidades de aplicativos computacionais. Esses sistemas são utilizados quando não se quer desenvolver em detalhes a implementação de softwares, mas apenas utilizar serviços e funcionalidades disponíveis, em particular, no ciberespaço.

As API's dos sistemas operacionais costumam ser dissociadas de tarefas mais essenciais, como manipulação de dados de memória e acesso a dispositivos computacionais específicos. A proposta é a apropriação de informações em portais públicos como o You Tube (disponível em http://www.youtube.com), Flickr (disponível em http://flickr.com) e Google 
Maps - (disponível em http://maps.google.com) e outros que disponibilizam API para produção de mashups e estimular a co-criação e a participação de novos usuários na construção de conteúdo compartilhado sobre a cidade e seu imaginário.

Com a cultura remix desenvolvemos os mashups que são sistemas que permitem a atuação de pessoas que desejam contemplar dados combinados de fontes distintas. Esse tipo de agenciamento cognitivo atua como um tipo de plataforma que permite a construção de novas narrativas a partir de bases de informações já estabelecidas, combinadas e modificadas por novas narrações, estimuladas pela participação dos habitantes dos bairros em estudo bem como de usuários na internet. Com isso, a proposta tem por finalidade construir uma cartografia conceitual - afetiva, cultural, com base nas experiências vividas nos territórios determinados, resultando num mapeamento indicativo das dinâmicas culturais locais, revelando a constante mutabilidade da fisionomia da região central da cidade de São Paulo.

As informações estão sendo armazenadas numa base de dados e conectadas às redes já existentes, incorporando as propostas desenvolvidas no programa de workshops e residências artísticas com a realização de intervenções urbanas, fórum de direitos culturais, mostra processual performativa e lançamento de publicações, permitindo interações de usuários da internet, coletivo de artistas iberoamericanos e agentes locais.

Uma convocatória aberta à participação da comunidade local foi lançada no Bom Retiro e reeditada na Barra Funda como parte das ações de conexão criativa com o território onde se situa o Instituto de Artes da UNESP como forma de mobilização de acervos privados que configuram a história pública, relacionadas às diferentes camadas de tempo e de espaço traduzidas na presença histórica e no sentido de pertencimento e identidade relativas aos territórios. Tais interações estão estruturando maquetes digitais compostas por fotografias e vídeos produzidos por participantes e moradores do bairros nos quais se processam as investigações-intervenções. Localizadas nos respectivos lugares de acontecimento, as imagens correspondem a uma iconografia das territorialidades e temporalidades locais, espécie de mosaico, palimpsesto de imagens anônimas, estruturadas e disponíveis no Google Maps. Cartografia mutante da memória pública contemporânea configura-se a partir das experiências vividas, micro-histórias urbanas que constituem a fisionomia da cidade em constante transformação. 
Pretende-se, portanto, a elaboração de uma cartografia de territórios urbanos específicos, incorporando as tecnologias digitais georeferenciadas, as ações coletivas e as práticas artísticas, oferecendo-se um ambiente colaborativo de desenvolvimento em rede de micro-processos criativos que possibilitem a revitalização urbana local, elaboração e disponibilização de conteúdo aberto como ferramenta para a construção de mapas conceituais e afetivos para o reconhecimento de territórios onde acontecem e aconteceram as ações artísticas e comunicativas.

Com a evolução de softwares livres de compartilhamento de informações e gestão de conteúdo chegamos a um grande momento de apropriação das Tecnologias da Informação e da Comunicação. Novas ferramentas tecnológicas permitem a criação de ambientes colaborativos baseados em conteúdo aberto e na gestão do conteúdo pelos usuários, em que tanto pesquisadores, artistas e pessoas em geral podem construir e compartilhar igualmente as suas criações, informações e conhecimentos.

Sejam ambientes em sistema do tipo Wiki - onde todos podem colaborar com o material disponibilizado, editando e/ ou adicionando informações aos temas propostos, ou sites que propõem conteúdo gratuito, ou até plataformas onde se podem criar projetos, comunidades e grupos de discussão. Essa proposta tem por finalidade construir uma cartografia dos sentidos, que emerge da ação conceitual com base nas experiências vividas no território, bem como narrativas desenvolvidas no decorrer do projeto a partir de workshops, intervenções urbanas, permitindo interações do público urbano e de usuários da internet.

Ao observarmos a mobilidade nesta produção artística, partimos da compreensão de que o homem é um ser da locomoção (A Cidade como Laboratório Urbano - Escola de Chicago 1930).

O habitante da cidade moderna desloca-se constantemente e pode trocar de status e de papel social em função dessa mobilidade, assim, definimos a mobilidade social e o lugar da habitação. Também encontramos a mobilidade sem deslocamento: mobilidade que cria uma massa, a mobilidade social pela moda que nos faz aderir ao comum e ao mesmo tempo nos diferencia.

Mobilidade informacional diz respeito à capacidade cognitiva de deslocamento por bens simbólicos, por mensagens, por informações: patrimônios migrantes. Os territórios informacionais - agora telemáticos e digitais - estão em expansão planetária, utilizam ferramentas ubíquas e permitem mobilidade informacional [emissão e recepção de informação] acoplada a uma mobilidade pelo espaço urbano. Permite uma 
nova maneira de compreender, dar sentido, criar vivências e experiências estéticas nos espaços das cidades contemporâneas configurando novas cartografias: geopoéticas.

\section{Referências}

AMARAL, Lilian, BARBOSA, Ana Mae. Interterritorialidade: mídias, contextos, educação. São Paulo : Edições SESC/ Editora Senac, 2009.

DELEUZE, Giles. Crítica e Clínica. São Paulo: Editora 34, 1997.

COSTA, Mario. O sublime tecnológico. São Paulo: Experimento, 1994.

LEMOS, André. Experiência estética em redes sociais. Palestra realizada no Seminário: Artes Plásticas e Comunicação na Contemporaneidade em 23/10/2008. Casa Fiat de Cultura. Belo Horizonte/MG. Projeto Sempre Um Papo. Disponível em http://www.youtube.com/ watch? $=X_{4}$ EEoQ33nM

FRANÇOIS, Perroux.. Dialogue des monopoles et des nations : "équilibre" ou dynamique des unités actives. Grenoble, Presses Universitaires de Grenoble,1982.

SANTOS, Milton. Por uma outra globalização - do pensamento único à consciência universal. São Paulo: Record, 2000. - A natureza do Espaço: Técnica e Tempo, Razão e Emoção. $4^{\underline{a}}$ ed. São Paulo: Editora da Universidade de São Paulo, 2004.

ZOURABICHVILI, Francois. O Vocabulário de Deleuze. Tradução André Telles. Rio de Janeiro: Coleção Conexões, 2009.

Recebido em: 10/01/2013

Aceito em: 10/01/2013

\section{LILIAN AMARAL}

lilianamaral@uol.com.br

Artista visual, curadora e pesquisadora. Doutora em Artes pela ECA

/ USP e Universidade Complutense de Madrid. Pesquisadora das Uiversidades Complutense de Madrid, UDG/ Girona, UB - Barcelona / Espanha. Pós-Doutora e Pesquisadora Cnpq pelo GIIP/ IA - UNESP onde Coordena a Linha de Pesquisa Arte e Media City com foco em Estratégias Contemporâneas para incidir sobre o Patrimônio. 